\title{
Study on Leakage and Diffusion Law of "Large Breathing" Loss of Gasoline Storage Tank Based on PHAST
}

\author{
Hai-Juan PAN ${ }^{1, a}$, Jun-Bo ZHOU ${ }^{1, b}$, Liang-Chao $\mathrm{CHEN}^{1, \mathrm{c}}$, Jian-Feng YANG ${ }^{1, \mathrm{~d},{ }^{*}}$ \\ and Xin-Yuan LU ${ }^{2, e}$
}

${ }^{1}$ Beijing University of Chemical Technology, Beijing, 100029, China

${ }^{2}$ China special Equipment Inspection and Research Institute, Beijing, 100029, China

a804544314@qq.com, bzhogab@163.com, cclcvip@vip.qq.com, dyjf01@263.net,

luxinyuan@csei.org.cn

*Jian-Feng Yang

Keywords: Breathing loss, Volatile organic compounds, PHAST, Diffusion law

\begin{abstract}
Volatile organic compounds (VOCs) from breathing loss of storage tanks account for more than $50 \%$ in chemical enterprises, so it is necessary to study the leakage and diffusion law of breathing loss in tank areas. In this paper, the empirical formula of China Petrochemical system was used to calculate the "large breathing" loss of the internal floating roof gasoline tank, and the diffusion simulation of "large breathing" loss of a petrochemical gasoline tank was carried out by PHAST. Because there is no "breathing loss" model of tank in PHAST, a user-defined model was used to simulate the "large breathing" loss of gasoline tank with internal floating roof. The simulation results show that when the atmospheric stability is constant, the greater wind speed is, the larger diffusion distance of VOCs is at the same time. When the wind speed is constant, the more unstable atmospheric stability is, the larger diffusion distance of VOCs is at the same time. When the wind speed is constant, the more stable atmosphere is, the higher concentration of VOCs is at the same location. The more unstable atmosphere is, the higher wind speed is, the more VOCs could be enriched near the storage tank in downwind direction. The simulation results provide reference for safe operation and division of emergency area, and provides reasonable theoretical support for safety management and safety evaluation.
\end{abstract}

\section{Introduction}

With the development of petroleum industry, the number of oil storage tanks increases year by year, and the proportion of volatile organic compounds (VOCs) emitted from tanks in petrochemical industry is more than 50\% [1]. According to statistics an average of 10 million tons of VOCs are emitted from organic liquid storage tanks to the atmosphere in China every year [2]. The fugitive emission of VOCs from tank area not only causes huge economic loss, but also deteriorates outdoor air quality [3]. VOCs can induce reduction of agricultural yield and serve as primary precursors for secondary organic aerosol (SOA) [4], which makes contributions to particulate pollution during haze events in China [5], also causes both acute and chronic health effects [6].

The fugitive emission of VOCs of floating roof tank is mainly divided into "large and small breathing” loss, what's more, "large breathing” loss is known as loss of hanging wall. VOCs emitted by petrochemical enterprises mainly come from fugitive emissions such as "large and small breathing” loss and sealing leakage of tank [7].

In this paper, the empirical formula of China Petrochemical system was used to calculate the "large breathing" loss of the internal floating roof gasoline tank, and PHAST was used to study the diffusion law of "large breathing" loss of gasoline storage tank. According to the influence of wind speed and atmospheric stability on the diffusion of VOCs, the concentration distribution of VOCs in tank area and the area that may be enriched by VOCs were estimated when discharging oil under different meteorological conditions. 


\section{Research Status of “Large Breathing” Leakage of Storage Tank}

\section{Research Status of Leakage Calculation}

At present, the calculation methods of "large breathing" loss of storage tanks at home and abroad mainly include semi-empirical semi-theoretical formula and pure empirical formula [8]. The semiempirical and semi-theoretical formulas mainly include the empirical formulas of China's petrochemical system, the methods recommended by the US Environmental Protection Agency (EPA), and the "Design guideline for energy conservation of petroleum depots". The pure empirical formula method mainly includes the domestic experience method of "Loss of bulk petroleum liquid products", the European Union emission coefficient method and the American Petroleum Institute (API) experience method. The pure empirical formula method has disadvantages of narrow application scope and poor calculation precision. For example, the empirical method of the American Petroleum Institute (API) is a formula obtained by statistical analysis of a large number of experimental data. The meteorological parameters, operation and management level adopted in the method are different from those used in China, and the difference in calculation of domestic storage tanks is large. In the semi-empirical and semi-theoretical formula, the TANK4.0.9 model database in the EPA recommendation method of the United States is only suitable for the calculation of storage tanks in the United States and requires unit conversion, and the calculation process is complex and the practical application is very difficult [9]. "Design guideline for energy conservation of petroleum depots" and the empirical formula of China petrochemical system are based on China's own situation, and based on the ideal gas state equation; the empirical calculation formula proposed through theoretical analysis has a rigorous derivation process and high credibility [10]. Compared with the "Design guideline for energy conservation of petroleum depots", the empirical formula of China petrochemical system is simple to calculate and accurate, which is more applicable to the calculation of oil loss of domestic storage tanks [11].

\section{Research Status of Gas Diffusion Law}

Hundreds of gas diffusion mathematical models have been established at home and abroad since the 1960s. The commonly used models include gauss model, BM model, FEM3 model and fluid mechanics model. Because the theoretical basis of these models is different, the application conditions are different. Ha [12] used FLUENT software to simulate the gas leakage process of the oil tank. He studied the effect of different operating pressure on the diffusion of different gases, but he did not calculate the leakage and leakage rate of VOCs during the process of discharging oil of the tank in the actual situation. Zhu et al. [13] used PHAST to simulate the diffusion of gases. The model took into account of the temperature, humidity, wind direction and so on, but didn't consider the effect of atmospheric stability on the gas diffusion.

In this paper, the empirical formula of China petrochemical system was adopted to calculate the oil loss of the tank of internal floating roof gasoline, and the leakage and diffusion law of VOCs was studied by using PHAST software.

\section{Introduction to PHAST Software}

Process Hazard Analysis Software Tool (PHAST) applies the computer to calculate the scope of influence and degree of hazard of the established model and generates the simulation analysis diagram and detailed simulation results report [14]. In addition, compared with the fluid mechanics model, PHAST is based on Newton's second law, N-S equation and energy conservation law, and takes the physical and chemical properties of hazardous chemicals in to account, and its results are similar to the experimental data, so it is widely used in the field of petrochemical industry. 


\section{Simulation Calculation of “Large Breathing” Loss of Storage Tank \\ Leakage Calculation}

According to the calculation formula of "large breathing" loss of typical internal floating roof tank in petrochemical system:

$$
\mathrm{L}_{\mathrm{W}}=4 \mathrm{Q} 1 \mathrm{CV} / \mathrm{D} \text {. }
$$

Where $\mathrm{L}_{\mathrm{w}}$ is large breathing loss of the internal floating roof tank, $\mathrm{kg} / \mathrm{a} ; \mathrm{Q}_{1}$ is annual turnover, $10^{3} \mathrm{~m}^{3} / \mathrm{a}$; D is diameter of tank, $\mathrm{m}$; $\mathrm{V}$ is average density of petroleum products, $\mathrm{kg} / \mathrm{m}^{3}$; $\mathrm{C}$ is sticking coefficient of tank wall, $\mathrm{m}^{3} / 1000 \mathrm{~m}^{2}$, its numerical value is related to the material of the tank wall. The material parameters of gasoline tank wall are shown in table 1.

Table 1 Sticking coefficient of tank wall $\left[\mathrm{m}^{3} / 1000 \mathrm{~m}^{2}\right]$.

\begin{tabular}{|c|c|c|c|}
\hline \multirow{2}{*}{ Storage medium } & \multicolumn{3}{|c|}{ Tank wall condition } \\
\cline { 2 - 4 } & Light rust & Heavy rust & Spray lining \\
\hline Gasoline & 0.00257 & 0.01284 & 0.2567 \\
\hline
\end{tabular}

The relevant parameters of the storage tank of a petrochemical company in Yunnan are listed in Table 2.

Table 2 Relevant parameters of the storage tank of a petrochemical company in Yunnan.

\begin{tabular}{|c|c|c|c|c|}
\hline $\begin{array}{c}\text { Storage } \\
\text { medium }\end{array}$ & $\begin{array}{c}\text { Diameter } \\
{[\mathrm{m}]}\end{array}$ & Density $\left[\mathrm{kg} / \mathrm{m}^{3}\right]$ & $\begin{array}{c}\text { Pump flow } \\
{\left[\mathrm{m}^{3} / \mathrm{h}\right]}\end{array}$ & $\begin{array}{c}\text { Annual turnover } \\
{\left[\mathrm{m}^{3} / \mathrm{a}\right]}\end{array}$ \\
\hline Gasoline & 28 & 790 & 500 & 633 \\
\hline
\end{tabular}

According to the calculation, each gasoline tank in the petrochemical company has "large breathing" loss of $182.727 \mathrm{~kg}$ in a year. The duration of oil charging: $t=Q_{1} / Q=1,260 \mathrm{~h}$, so the average loss of "large breathing" loss is $0.145 \mathrm{~kg}$ per hour.

\section{Simulation Parameter Setting}

The user defined source model is selected to simulate the "large breathing" loss of gasoline storage tank, and the simulation parameters are listed in table 3.

Table 3 Diffusion simulation parameter values

\begin{tabular}{|c|c|c|c|c|c|}
\hline Losses [kg] & $\begin{array}{c}\text { Time of } \\
\text { losses [s] }\end{array}$ & $\begin{array}{c}\text { Rate of } \\
\text { losses [kg/s] }\end{array}$ & $\begin{array}{c}\text { Temperature } \\
{\left[{ }^{\circ} \mathrm{C}\right]}\end{array}$ & $\begin{array}{c}\text { Relative } \\
\text { humidity }\end{array}$ & $\begin{array}{c}\text { Surface } \\
\text { roughness }[\mathrm{m}]\end{array}$ \\
\hline 0.145 & 3600 & 0.0004028 & 20 & $70 \%$ & 0.18 \\
\hline
\end{tabular}

On the choice of atmospheric stability, refer to Pasqill stability classification table, A, B, C, D, E and $\mathrm{F}$ are classified into six grades: strong unstable, unstable, weak unstable, neutral, relatively stable and stable. In this paper, the common stability in the corresponding wind speed was selected for simulation.

\section{Simulation Results and Analysis}

According to the Pasqill stability rating table, the leakage and diffusion of "large breathing" loss of gasoline tank was simulated under different wind speeds and atmospheric stability. 


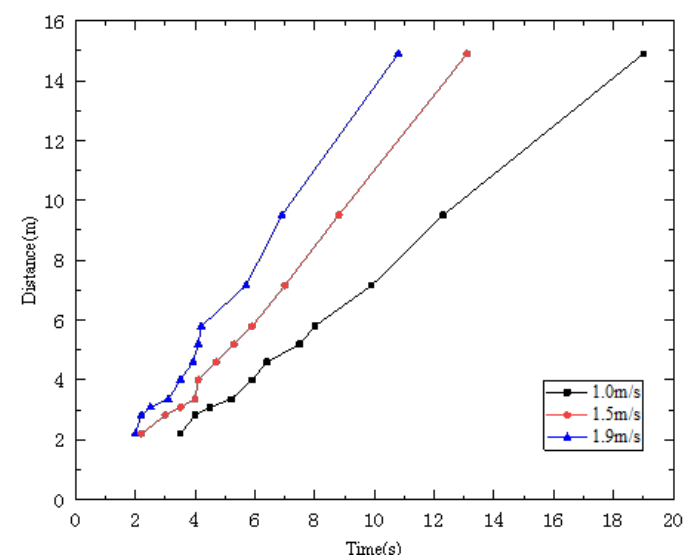

Fig. 1 The variation of diffusion distance of VOCs with time under different wind speeds and A atmospheric stability.

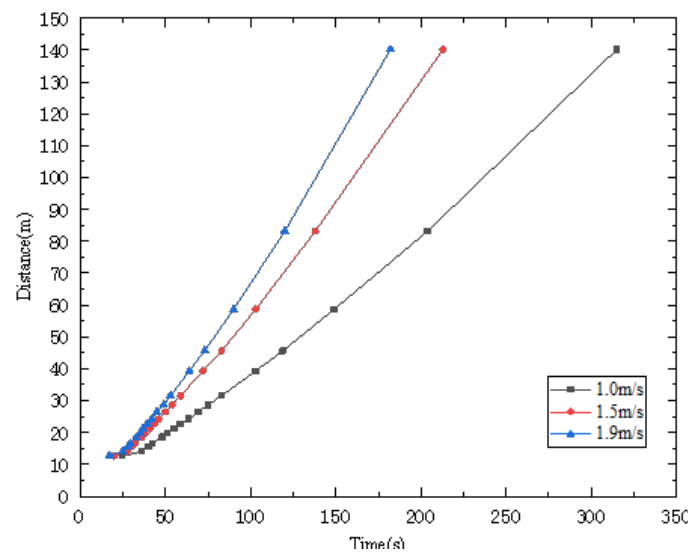

Fig. 2 The variation of diffusion distance of VOCs with time under different wind speeds and F atmospheric stability.

Fig. 1 and Fig. 2 respectively showed the change of diffusion distance of VOCs with time under different wind speeds and atmospheric stability. The slope of each curve was diffusion rate of VOCs under different conditions. It could be seen from Fig. 1and Fig. 2 that the greater wind speed is, the stronger transport effect of the wind on VOCs is, and the larger diffusion distance of VOCs is at the same time. From the comparison of Fig. 1 and Fig. 2, it's known that under the same wind speed, the more unstable atmosphere is, the stronger effect of the wind on VOCs is, and the larger diffusion distance of VOCs is at the same time.

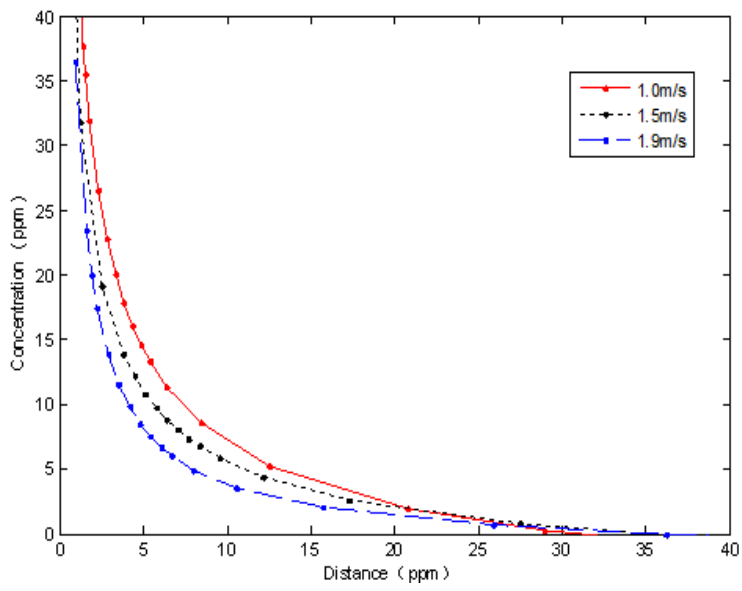

Fig. 3 Concentration distribution of VOCs under different wind speeds and A atmospheric stability. 


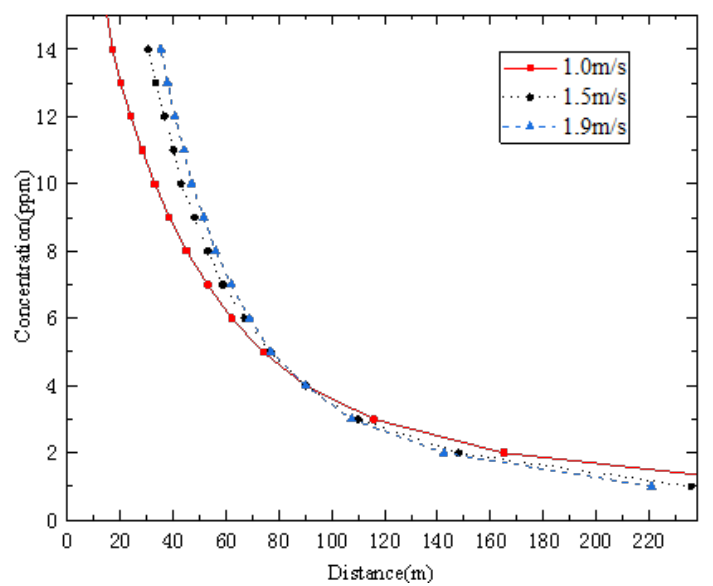

Fig. 4 Distribution of VOCs concentration under different wind speeds and F atmospheric stability.

As shown in Fig. 3, when the wind speed is lower than $2 \mathrm{~m} / \mathrm{s}$ and the atmospheric stability is A, the higher wind speed is, the stronger dilution effect of wind on VOCs is, and the lower concentration of VOCs is at the same location. Therefore, when the atmospheric stability is A, the concentration distribution of VOCs is greatly affected by wind dilution. In addition, when the atmospheric stability is constant, the higher wind speed is, the further diffusion distance of VOCs is.

As shown in Fig. 4, when atmospheric stability is F and concentration of VOCs is more than 4ppm, the faster wind speed is, the greater transmission effect of wind is, and the higher accumulation concentration of VOCs is at the same location. when atmospheric stability is F and the concentration of VOCs is lower than 4ppm, the faster wind speed is, the greater effect of wind dilution is, and the lower concentration of VOCs is at the same location.

The comparison between Fig. 3 and Fig. 4 showed that when wind speed is constant, the more stable atmosphere is, the farther diffusion distance of VOCs is; the more unstable atmosphere is, the greater influence of wind dilution on concentration distribution of VOCs is.

Due to the average wind speed is $2.2 \mathrm{~m} / \mathrm{s}$ in the area where the petrochemical company is located, simulations of "large breathing" loss of gasoline tanks were carried out under different atmospheric stability, and the simulation results are shown in Fig. 5 and Fig. 6.

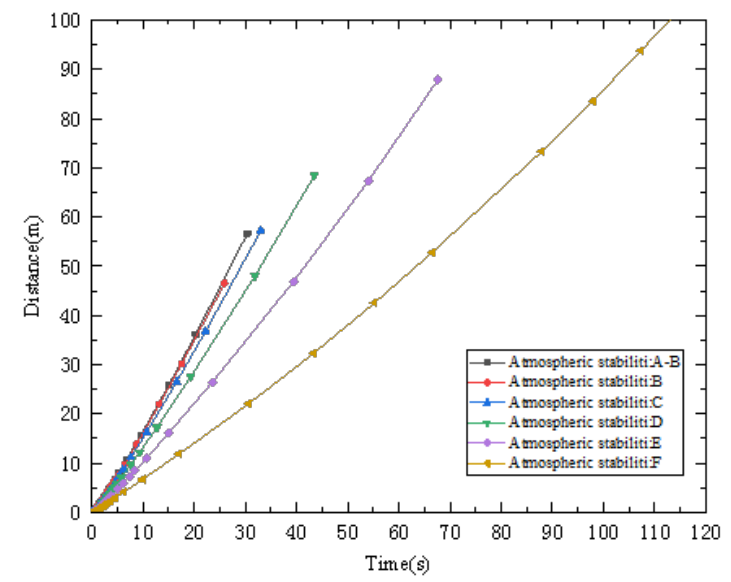

Fig. 5 The variation of VOCs diffusion distance with time under wind speed of $2.2 \mathrm{~m} / \mathrm{s}$ and different atmospheric stability. 


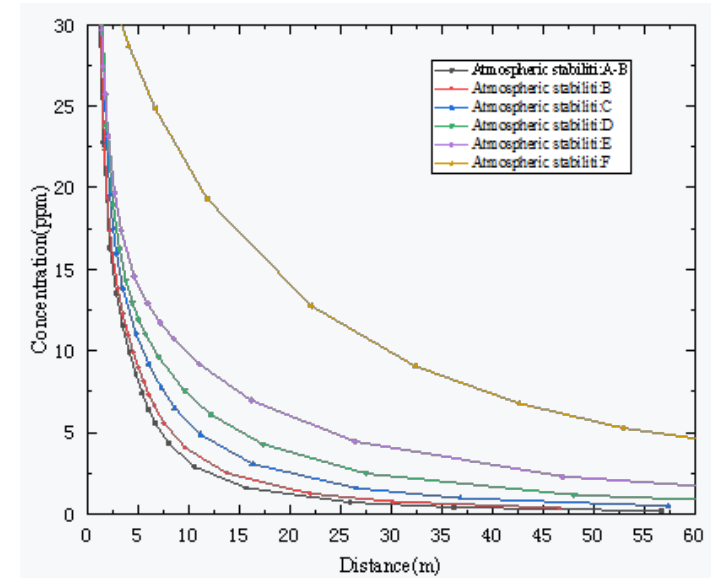

Fig. 6 Distribution of VOCs concentration under wind speed of 2.2m/s and different atmospheric stability.

As can be seen from Fig. 5, when the wind speed is $2.2 \mathrm{~m} / \mathrm{s}$, the more unstable atmosphere is, the stronger transport effect of wind on the VOCs is, and the larger diffusion distance of VOCs is at the same time. As can be seen from Fig. 6, the more unstable the atmosphere is, the weaker dilution effect of wind on VOCs is, and the higher concentration of VOCs is at the same location.

What's more, the concentration distribution of VOCs is linearly correlated with the distance, and the closer it is to the storage tank, the higher concentration of VOCs is. In conclusion, when the wind speed is constant, the higher atmospheric stability is, the more VOCs can be enriched near the storage tank in downwind direction.

\section{Conclusions}

In this paper, the following conclusions were obtained by using the empirical formula of China petrochemical industry system to calculate the "large breathing" loss of internal floating roof gasoline storage tank and using PHAST for diffusion simulation:

(1) The diffusion of "large breathing" loss of gasoline storage tanks is greatly affected by wind speed and atmospheric stability. When the atmospheric stability is constant, the greater wind speed is, the larger diffusion distance of VOCs is at the same time. When the wind speed is constant, the more unstable atmospheric stability is, the larger diffusion distance of VOCs is at the same time.

(2) The concentration distribution of VOCs is linearly correlated with the distance, and the closer it is to the storage tank, the higher concentration of VOCs is. When wind speed is constant, the more stable atmosphere is, the higher concentration of VOCs is at the same location. When atmospheric stability is A, the higher wind speed is, the lower concentration of VOCs is at the same location. When atmospheric stability is $\mathrm{F}$, the higher the wind speed is, the higher concentration of VOCs is at the same location where the concentration of VOCs is more than 4ppm, the lower concentration of VOCs is at the same location where the concentration of VOCs is less than 4ppm.

(3) The more unstable atmosphere is, the higher wind speed is, the more VOCs can be enriched near the storage tank in downwind direction.

\section{References}

[1] J. Lu, A study on VOCs emission inventory of typical petrochemical plant and its local emission factor, J. Environ. Poll. Con. 39 (2017) 604-609.

[2] X.S. Zhou, S.H. Cui, L. Tong, Study and practice of pollution sources and estimation methods for volatile organic compounds in petrochemical industry. China Environ. Sci. Pre, Beijing, 2015, pp. 89-90. 
[3] J.E. Lerner, T. Kohajda, M.E. Aguilar, et al, Improvement of health risk factors after reduction of VOCs concentrations in industrial and urban areas, Environ. Sci. Poll. Res. Int. 21 (2014) 96769688.

[4] D. Han, S. Gao, Q. Fu. et al, Do volatile organic compounds (VOCs) emitted from petrochemical industries affect regional PM2.5, J. Atm. Res. 209 (2018) 123-130.

[5] R.J. Huang, Y.L. Zhang, C. Bozzetti, et al, High secondary aerosol contribution to particulate pollution during haze events in China, J. Nat. 514 (2014) 218-22.

[6] T. Petry, D. Vitale, F.J. Joachim, et al, Human health risk evaluation of selected VOCs, SVOCs and particulate emissions from scented candles, J. Reg. Toxic. Pharma. 69 (2014) 55-70.

[7] M.L. He, H.L. Xiao, X.F. Chen, et al, Emission characteristics of volatile organic compounds in chemical industry park based on emission links, J. China Environ. Sci. 37 (2017) 38-48.

[8] Z.H Jia, Study on risk analysis of tank farm and estimation of tank's evaporation loss in petroleum storage and transportation, D. China Univ. Min. Tech. (2014).

[9] Environmental engineering assessment center of the ministry of environmental protection. Technical guide for VOCs emission estimation method in environmental assessment of petrochemical construction projects, J. 03 (2014).

[10] Z.W. Wang, W.J. Wang, Z. Wang, et al, Research on petrochemical enterprise fugitive emission forecast method, J. Guangzhou chem. Indus. 43 (2015) 156-160.

[11] Y.F. Ji, Study on atmospheric environmental impact assessment of fugitive emission emitted by oil transportation station, D. Xi'an Univ. Tech. (2012).

[12] L. Ha, The study on the aided classifications method of hazardous areas of explosive gas atmospheres based on numerical simulation, D. Cap. Univ. Econ. Tr. (2008).

[13] Z.J Lin, Application of flammable gas dispersion modeling in hazardous area classification for offshore oil and gas production facility, J. Shi. Bui. China. (2008).

[14] H.J. Pan, G.Q. Liu, J.B. Zhou, Comparative research on diffusion simulation software of hazardous chemicals leakage accident in port area, J. China Wat. Trans. 18 (2018) 84-85+88. 